\title{
KOMPETENSI PENDIDIK PAUD PADA LEMBAGA PAUD (KELOMPOK BERMAIN) BINAAN BPKB SULAWESI TENGGARA
}

\author{
La Ode Tomo*
}

\begin{abstract}
The purpose of this research was to describe the competence of educators in early childhood education institutions in South East Sulawesi. Data were collected using interview guides and document study to be analysed qualitatively. This research concludes the need to improve the educators' competences and provides some recommendations to do.
\end{abstract}

Keywords: early childhood education, golden age, physical and mental development.

\section{PENDAHULUAN}

Anak-anak merupakan aset bangsa dan diharapkan merekalah kelak yang akan memutar roda Pemerintahan. Oleh karena itu, sebagai generasi penerus bangsa, anak memerlukan pembinaan dan pengembangan yang optimal sejak usia dini melalui peran pendidik (guru) dan orang tua.

Peran pendidik dalam dunia pendidikan anak adalah bertanggung jawab secara moral untuk mengembangkan kemampuan dan membentuk watak dalam rangka mencerdaskan kehidupan anak bangsa. Adapun tujuannya adalah untuk mengembangkan potensi anak agar menjadi manusia yang beriman dan bertakwa kepada Tuhan Yang Maha Esa, berakhlak mulia, sehat, berilmu, cakap, kreatif, mandiri, dan menjadi warga negara yang bertanggung jawab untuk bangsa dan negara.

Seiring dengan upaya peningkatan mutu program Pendidikan Anak Usia Dini (PAUD) dan mutu pendidik, maka Pamong Belajar BPKB Sulawesi Tenggara melaksanakan pendataan pada bulan Agustus 2008 dan memperoleh gambaran data perkembangan kesadaran masyarakat terhadap dunia pendidikan anak sepuluh tahun terakhir ini di wilayah provinsi Sulawesi Tenggara. Kenyataan di lapangan menunjukan bahwa jumlah lembaga PAUD mengalami peningkatan yang sangat signifikan, demikian juga jumlah pendidik sampai tahun 2008 ini, jumlah pendidik pada lembaga PAUD adalah 591 orang dan yang dapat terlatih adalah 100 orang. Dengan demikian yang belum terbina melalui diklat masih tersisa 491 orang (database PTK-PNF, 2008).
Berdasarkan data di atas, dapat dilihat bahwa jumlah lembaga PAUD tidak didukung oleh jumlah pendidik yang berkualitas. Hal ini disebabkan karena sebagian besar pendidik hanya tamatan SMA atau SMK atau yang sederajat (379 orang) sedangkan tamatan Diploma dan Sarjana berjumlah 212 orang. Dari kondisi ini muncul pada pertanyaan, bagaimana kompetensi pendidik dalam mengelola proses pembelajaran. Proses pembelajaran seharusnya mampu melatih peserta didik untuk mengembangkan kreativitas, imajinasi, ekspresi diri dan kemampuan pemecahan masalah serta dapat menghayati alam sekitarnya.

Salah satu indikator dalam membahas tentang kompetensi pendidik dalam mengelola proses pembelajaran pada PAUD adalah upaya dan kinerja pendidik. Upaya dan kinerja pendidik yang dimaksudkan dalam hal ini adalah berkaitan dengan pelaksanaan peran dan fungsinya sebagai pendidik dalam mengelola proses pembelajaran/pekerjaan tertentu. Selanjutnya sesuai yang diamanatkan dalam Undang-Undang No. 20 tahun 2003 pada Bab I tentang sistem Pendidikan Nasional, menjelaskan bahwa yang dimaksud dengan kompetensi adalah sekumpulan pengetahuan, keterampilan, sikap dan nilai-nilai yang diwujudkan dalam kebiasaan berpikir dan bertindak. Oleh karena itu, pendidik pada lembaga PAUD diharapkan memiliki pengetahuan mendidik secara profesional dan merupakan syarat mutlak untuk memikul tanggung jawab mendidik yang harapannya dapat meningkatkan harkat dan martabat anak bangsa.

Dalam upaya menepis keraguan atas kualitas pendidik anak usia dini perlu adanya upaya secara terusmenerus meningkatkan kualitas dan kinerja pendidik. Langkah-langkah yang perlu dilaksanakan untuk 
mencapai hal tersebut di antaranya adalah dengan mengetahui tingkat kemampuan pendidik. Hal ini sangat penting untuk dilakukan karena sampai pada saat ini belum ada data konkret yang menggambarkan kompetensi pendidik lembaga PAUD sebagai bahan dasar pembinaan dan pemberian kegiatan untuk meningkatkan kualitas pendidik pada lembaga PAUD.

Berdasarkan uraian latar belakang judul ini maka penulis akan memfokuskan permasalahan penelitian sebagai berikut. Bagaimana tingkat kompetensi pendidik PAUD pada Kelompok Bermain binaan BPKB Sulawesi Tenggara?

Penelitian ini diharapkan dapat memberikan gambaran kompetensi pendidik PAUD binaan BPKB Sulawesi Tenggara. Gambaran tersebut memberikan deskripsi tingkat kompetensi yang dimiliki oleh pendidik PAUD untuk mendukung penyelenggaraan pem-belajaran pada program PAUD sesuai dengan tugas pokok pendidik sebagai berikut.

Oleh karena itu, hasil penelitian ini diharapkan dapat memberikan manfaat antara lain untuk (1) memformulasikan data kemampuan pendidik PAUD di Sulawesi Tenggara yang diperuntukan bagi perumusan kebijakan program pengembangan kemampuan pendidik di daerah, dan (2) memformulasikan data kebutuhan pembinaan dan diklat pendidik PAUD.

\section{KAJIAN TEORETIS}

Seorang tenaga pendidik bertugas untuk mentransfer pengetahuan dan menanamkan nilai-nilai yang baik, serta mengembangkan kompetensi peserta didik. Filosofi Ki Hajar Dewantara yang digunakan dalam asas pendidikan nasional, berbunyi : "Ing ngarso sung tulodo, ing madya mangun karso, tut wuri handayani", memiliki makna sebagai berikut. Pertama, Ing ngarso sung tulodo artinya di depan memberikan teladan. Berdasarkan makna tersebut, seorang pendidik harus memberikan contoh dan teladan yang baik dalam mengubah perilaku peserta didik. Kedua, Ing madya mangun karso artinya di tengah memberikan kesempatan untuk berkarya. Berdasarkan makna tersebut seorang pendidik harus menjadi fasilitator yang memfasilitasi peserta didik untuk menciptakan suatu gagasan atau suatu karya. Ketiga,Tut wuri handayani artinya dari depan memberikan arahan dan dari belakang memberikan dorongan. Dalam hal ini seorang pendidik harus memberikan arahan, bimbingan, dan dorongan terhadap peserta didik untuk menjalankan nilai-nilai dan perilaku yang diajarkan.

Berdasarkan filosofi tersebut, kita sadari bahwa tugas dan peranan seorang pendidik tidaklah mudah. Oleh karena itu, seorang pendidik harus memiliki empat kompetensi yaitu pedagogik, kepribadian, sosial, dan profesional sebagaimana dijelaskan dalam Standar Nasional Pendidikan (SNP).

Sesuai peran, tugas dan tanggung jawabnya sebagai pendidik pada lembaga PAUD maka seorang pendidik dituntut dan bertanggung jawab dalam memberikan pelayanan pembelajaran kepada peserta didik. Dalam proses pembelajaran peserta didik merupakan "output" atau keluaran dari penyelenggaraan pendidikan yang perlu dipertahankan kualitasnya sebagai indikator kualitas pendidikan nasional. Menurut Sunarjo dan Latifah (1994:169) pelayanan kepada peserta didik sebaiknya diarahkan pada aspek (1) Perkembangan kreativitas, bakat, dan minat peserta didik; (2) keikutsertaan dalam mengikuti kegiatankegiatan pada lembaga pendidikan di mana mereka memperoleh pengetahuan, pengalaman, keterampilan secara langsung melalui proses belajar mengajar; (3) sikap mandiri serta disiplin diri, percaya diri bahwa peserta didik memiliki potensi positif yang dapat dikembangkan; (4) pengembangan moral dan etika pada peserta didik; dan (5) kebutuhan peserta didik dalam menghadapi kesulitan belajar.

Untuk memenuhi tujuan tersebut seorang pendidik harus menguasai berbagai kemampuan dalam bidang akademis, didaktik, pedagogis, dan kematangan kepribadian dalam mengelola proses pendidikan pada lembaga PAUD.

Penyelenggaraan PAUD saat ini telah mengalami reformasi pendidikan dalam rangka mewujudkan pendidikan nasional yang bermutu yang diatur dalam Peraturan Pemerintah (PP) Nomor 19 Tahun 2005 Tentang Standar Nasional Pendidikan. Standar nasional pendidikan tersebut memiliki delapan standar pendidikan yang terdiri dari: (1) standar isi, (2) standar proses, (3) standar kompetensi lulusan, (4) standar pendidik dan tenaga kependidikan, (5) standar sarana dan prasarana, (6) standar pengelolaan, (7) standar pembiayaan, dan (8) standar penilaian pendidikan.

Standar pendidik dan tenaga kependidikan yang dimaksud adalah kriteria yang perlu dimiliki oleh tenaga pendidik, meliputi pendidikan prajabatan dan kelayakan fisik maupun mental serta pendidikan dalam jabatan. 
Seorang pendidik harus memiliki kualifikasi akademik dan kompetensi sebagai agen pembelajaran, sehat jasmani dan rohani, serta memiliki kemampuan untuk mewujudkan tujuan pendidikan nasional. Kompetensi yang dimaksudkan dalam standar pendidikan nasional tersebut meliputi kompetensi pedagogik-andragogi, kompetensi kepribadian, kompetensi sosial, dan kompetensi profesional.

1. Kompetensi Pedagogik merupakan kemampuan yang berkenaan dengan pemahaman peserta didik dan pengelolaan pembelajaran yang partisipatif dan logis. Secara subtantif kompetensi ini mencakup kemampuan pemahaman terhadap peserta didik, perancangan dan pelaksanaan pembelajaran, evaluasi hasil belajar dan pengembangan peserta didik untuk mengaktualisasikan berbagai potensi yang dimilikinya.

2. Kompetensi kepribadian adalah kemampuan pribadi yang mantap, stabil, dewasa, arif dan berwibawa, menjadi teladan bagi peserta didik dan berakhlak mulia. Oleh karena itu, pengembangan kompetensi kepribadian penting dilaksanakan dalam mendukung kompetensi lain karena kompetensi kepribadian yang melekat pada diri seorang pendidik merupakan modal utama dalam pengembangan kompetensi lainnya.

3. Kompetensi sosial berkenaan dengan kemampuan pendidik sebagai bagian dari masyarakat untuk berkomunikasi dan bergaul secara efektif dengan perserta didik atau warga belajar, sesama pendidik, tenaga kependidikan, orang tua atau wali peserta didik atau warga belajar, dan masyarakat sekitar.

4. Kompetensi profesional merupakan kemampuan yang berkenaan dengan penguasaan materi pembelajaran secara luas dan mendalam yang mencakup penguasaan substansi isi materi kurikulum, mata pelajaran disatuan pendidikan nonformal dan substansi keilmuan yang menaungi materi tersebut serta menambah wawasan keilmuan sebagai PTK-PNF.

\section{METODOLOGI PENELITIAN}

Pendekatan yang digunakan dalam kegiatan kajian kompetensi pendidik PAUD ini adalah metode kualitatif yang dianalisis secara deskriptif. Data dikumpulkan melalui wawancara dan studi dokumen. Wawancara adalah dipergunakan untuk menjaring data yang diperoleh langsung pada pendidik di lembaga PAUD (responden) melalui pengisian daftar pertanyaan wawancara (kuisioner) yang berhubungan dengan standar kompetensi pendidik yang meliputi (1) kompetensi pedagogik, (2) kompetensi kepribadian, (3) kompetensi sosial, dan (4) kompetensi profesional sedangkan studi dokumen dilakukan untuk menjaring data berupa dokumen yang ada hubungannya dengan penelitian ini.

Adapun yang menjadi populasi dalam penelitian ini adalah seluruh pendidik pada lembaga PAUD binaan BPKB Provinsi Sulawesi Tenggara yaitu sebanyak sepuluh orang. Sampel diambil secara keseluruhan populasi atau sampel total. Teknik analisa data yang dipergunakan adalah teknik analisa deskriptif, yakni mengambarkan hasil penelitian yang menggunakan persentase.

\section{HASIL PENELITIAN}

Berdasarkan data latar belakang pendidikan dari objek penelitian ini bahwa jumlah empat orang (40\%) adalah memiliki akta mengajar Diploma II dan tamatan
SMA enam orang (60\%). Adapun hasil penelitian kompetensi pendidik pada lembaga PAUD berdasarkan wawancara atau kuisioner dengan gambaran data berikut.

Tabel 1. Kompetensi Pedagogik

\begin{tabular}{|c|c|c|c|c|c|c|c|c|c|c|c|c|}
\hline \multirow{3}{*}{ No } & \multirow{3}{*}{ Aspek } & \multicolumn{11}{|c|}{ Kompetensi } \\
\hline & & \multicolumn{2}{|c|}{$\begin{array}{l}\text { Sangat } \\
\text { mampu }\end{array}$} & \multicolumn{2}{|c|}{ Mampu } & \multicolumn{2}{|c|}{$\begin{array}{l}\text { Cukup } \\
\text { mampu }\end{array}$} & \multicolumn{2}{|c|}{$\begin{array}{l}\text { Kurang } \\
\text { mampu }\end{array}$} & \multicolumn{2}{|c|}{$\begin{array}{l}\text { Tidak } \\
\text { mampu }\end{array}$} & \multirow[t]{2}{*}{ Total } \\
\hline & & Frek & $\%$ & Frek & $\%$ & Frek & $\%$ & Frek & $\%$ & Frek & $\%$ & \\
\hline 1. & $\begin{array}{l}\text { Memahami peserta } \\
\text { didik }\end{array}$ & 0 & 0 & 5 & 50 & 3 & 30 & 2 & 20 & 0 & 0 & 10 \\
\hline 2. & $\begin{array}{l}\text { Merancang } \\
\text { pembelajaran }\end{array}$ & 0 & 0 & 6 & 60 & 3 & 30 & 1 & 10 & 0 & 0 & 10 \\
\hline
\end{tabular}




\begin{tabular}{|c|c|c|c|c|c|c|c|c|c|c|c|c|}
\hline \multirow{3}{*}{ No } & \multirow{3}{*}{ Aspek } & \multicolumn{11}{|c|}{ Kompetensi } \\
\hline & & \multicolumn{2}{|c|}{$\begin{array}{l}\text { Sangat } \\
\text { mampu }\end{array}$} & \multicolumn{2}{|c|}{ Mampu } & \multicolumn{2}{|c|}{$\begin{array}{l}\text { Cukup } \\
\text { mampu }\end{array}$} & \multicolumn{2}{|c|}{$\begin{array}{l}\text { Kurang } \\
\text { mampu }\end{array}$} & \multicolumn{2}{|c|}{$\begin{array}{l}\text { Tidak } \\
\text { mampu }\end{array}$} & \multirow[t]{2}{*}{ Total } \\
\hline & & Frek & $\%$ & Frek & $\%$ & Frek & $\%$ & Frek & $\%$ & Frek & $\%$ & \\
\hline 3. & $\begin{array}{l}\text { Melaksanakan } \\
\text { pembelajaran }\end{array}$ & 0 & 0 & 10 & $\begin{array}{l}10 \\
0\end{array}$ & 0 & 0 & 0 & 0 & 0 & 0 & 10 \\
\hline 4. & $\begin{array}{l}\text { Merancang \& melaks. } \\
\text { evaluasi }\end{array}$ & 0 & 0 & 2 & 20 & 3 & 30 & 3 & 30 & 2 & 20 & 10 \\
\hline 5. & $\begin{array}{l}\text { Mengembangkan } \\
\text { kemampuan peserta } \\
\text { didik }\end{array}$ & 0 & 0 & 2 & 20 & 3 & 30 & 3 & 30 & 2 & 20 & 10 \\
\hline$n=5$ & Jumlah & 0 & 0 & 25 & $\begin{array}{l}25 \\
0\end{array}$ & 12 & $\begin{array}{l}12 \\
0\end{array}$ & 9 & 90 & 4 & 40 & 50 \\
\hline
\end{tabular}

Keterangan:

$\begin{array}{ll}\text { Sangat mampu } & =0 / 5=0 \% \\ \text { Mampu } & =250 / 5=50 \% \\ \text { Cukup mampu } & =120 / 5=24 \% \\ \text { Kurang mampu } & =90 / 5=18 \% \\ \text { Tidak mampu } & =40 / 5=8 \%\end{array}$

Dari tabel di atas, terlihat kompetensi pedagogik pendidik berada pada kategori sangat mampu $=0 \%$, kategori mampu menunjukkan angka 50\%, kategori cukup mampu menunjukkan angka 24\%, kategori kurang mampu menunjukkan angka $18 \%$ dan kategori tidak mampu menunjukkan angka $8 \%$ dari total responden.

Tabel 2. Kompetensi Kepribadian

\begin{tabular}{|c|c|c|c|c|c|c|c|c|c|c|c|c|}
\hline \multirow{3}{*}{ No } & \multirow{3}{*}{ Aspek } & \multicolumn{11}{|c|}{ Kompetensi } \\
\hline & & \multicolumn{2}{|c|}{ Sangat baik } & \multicolumn{2}{|l|}{ baik } & \multicolumn{2}{|c|}{$\begin{array}{l}\text { Cukup } \\
\text { baik }\end{array}$} & \multicolumn{2}{|c|}{$\begin{array}{l}\text { Kurang } \\
\text { baik }\end{array}$} & \multicolumn{2}{|c|}{ Tidak baik } & \multirow[t]{2}{*}{ Tota } \\
\hline & & Frek & $\%$ & Frek & $\%$ & Frek & $\%$ & Frek & $\%$ & Frek & $\%$ & \\
\hline 1. & $\begin{array}{l}\text { Memiliki kepribadian } \\
\text { yang mantap dan } \\
\text { stabil }\end{array}$ & 0 & 0 & 7 & 70 & 3 & 30 & 0 & 0 & 0 & 0 & 10 \\
\hline 2. & $\begin{array}{l}\text { Memiliki kepribadian } \\
\text { yang dewasa }\end{array}$ & 0 & 0 & 7 & 70 & 3 & 30 & 0 & 0 & 0 & 0 & 10 \\
\hline 3. & $\begin{array}{l}\text { Memiliki kepribadian } \\
\text { arif }\end{array}$ & 0 & 0 & 5 & 50 & 3 & 30 & 2 & 20 & 0 & 0 & 10 \\
\hline 4. & $\begin{array}{l}\text { Memiliki kepribadian } \\
\text { berwibawa }\end{array}$ & 0 & 0 & 5 & 50 & 3 & 30 & 2 & 20 & 0 & 0 & 10 \\
\hline 5. & $\begin{array}{l}\text { Memiliki kepribadian } \\
\text { akhlak mulia }\end{array}$ & 0 & 0 & 5 & 50 & 4 & 40 & 1 & 10 & 0 & 0 & 10 \\
\hline$n=5$ & Jumlah & 0 & 0 & 29 & $\begin{array}{l}29 \\
0\end{array}$ & 16 & $\begin{array}{l}16 \\
0\end{array}$ & 5 & 50 & 0 & 0 & 50 \\
\hline
\end{tabular}

\section{Keterangan:}

Sangat baik

Baik

Cukup baik

Kurang baik

Tidak baik

$$
\begin{aligned}
& =0 / 5=0 \% \\
& =290 / 5=58 \% \\
& =160 / 5=32 \% \\
& =50 / 5=10 \% \\
& =0 / 5=0 \%
\end{aligned}
$$

Dari tabel di atas, terlihat bahwa kompetensi kepribadian pendidik berada pada kategori sangat baik 0\%, kategori baik menunjukkan angka 58\%, kategori cukup baik menunjukkan angka 32\%, kategori kurang baik menunjukkan angka $10 \%$ dan kategori tidak baik menunjukkan angka $0 \%$ dari total responden. 
Tabel 3. Kompetensi Sosial

\begin{tabular}{|c|c|c|c|c|c|c|c|c|c|c|c|c|}
\hline \multirow{3}{*}{ No } & \multirow{3}{*}{ Aspek } & \multicolumn{11}{|c|}{ Kompetensi } \\
\hline & & \multicolumn{2}{|c|}{$\begin{array}{l}\text { Sangat } \\
\text { mampu }\end{array}$} & \multicolumn{2}{|c|}{ Mampu } & \multicolumn{2}{|c|}{$\begin{array}{l}\text { Cukup } \\
\text { mampu }\end{array}$} & \multicolumn{2}{|c|}{$\begin{array}{l}\text { Kurang } \\
\text { mampu }\end{array}$} & \multicolumn{2}{|c|}{$\begin{array}{l}\text { Tidak } \\
\text { mampu }\end{array}$} & \multirow[t]{2}{*}{ Total } \\
\hline & & Frek & $\%$ & Frek & $\%$ & Frek & $\%$ & Frek & $\%$ & Frek & $\%$ & \\
\hline 1. & $\begin{array}{l}\text { Berkomunikasi } \\
\text { dengan peserta didik }\end{array}$ & 2 & 20 & 8 & 80 & 0 & 0 & 0 & 0 & 0 & 0 & 10 \\
\hline 2. & $\begin{array}{l}\text { Berkomunikasi } \\
\text { dengan mitra secara } \\
\text { efektif }\end{array}$ & 0 & 0 & 3 & 30 & 5 & 50 & 2 & 20 & 0 & 0 & 10 \\
\hline 3. & $\begin{array}{l}\text { Berkomunikasi } \\
\text { dengan orang tua } \\
\text { anak \& masyarakat }\end{array}$ & 0 & 0 & 6 & 60 & 4 & 40 & 0 & 0 & 0 & 0 & 10 \\
\hline$n=3$ & Jumlah & 2 & 20 & 17 & $\begin{array}{l}17 \\
0\end{array}$ & 9 & 90 & 2 & 20 & 0 & 0 & 30 \\
\hline
\end{tabular}

\section{Keterangan:}

$\begin{array}{ll}\text { Sangat mampu } & =20 / 3=6,67 \% \\ \text { Mampu } & =170 / 3=56,66 \% \\ \text { Cukup mampu } & =90 / 3=30 \% \\ \text { Kurang mampu } & =20 / 3=6,67 \% \\ \text { Tidak mampu } & =0 / 3=0 \%\end{array}$

Dari tabel di atas, terlihat bahwa kompetensi sosial pendidik berada pada kategori sangat mampu $6,67 \%$, kategori mampu menunjukkan angka 56,66\%, kategori cukup mampu menunjukkan angka 30\%, kategori kurang mampu menunjukkan angka 6,67\% dan kategori tidak mampu menunjukkan angka $0 \%$ dari total responden.

Tabel 4. Kompetensi Profesional

\begin{tabular}{|c|c|c|c|c|c|c|c|c|c|c|c|c|}
\hline \multirow{3}{*}{ No } & \multirow{3}{*}{ Aspek } & \multicolumn{11}{|c|}{ Kompetensi } \\
\hline & & \multicolumn{2}{|c|}{$\begin{array}{l}\text { Sangat } \\
\text { mampu }\end{array}$} & \multicolumn{2}{|c|}{ Mampu } & \multicolumn{2}{|c|}{$\begin{array}{l}\text { Cukup } \\
\text { mampu }\end{array}$} & \multicolumn{2}{|c|}{$\begin{array}{l}\text { Kurang } \\
\text { mampu }\end{array}$} & \multicolumn{2}{|c|}{$\begin{array}{l}\text { Tidak } \\
\text { mampu }\end{array}$} & \multirow[t]{2}{*}{ Total } \\
\hline & & Frek & $\%$ & Frek & $\%$ & Frek & $\%$ & Frek & $\%$ & Frek & $\%$ & \\
\hline 1. & $\begin{array}{l}\text { Penguasaan materi } \\
\text { secara mendalam }\end{array}$ & 0 & 0 & 8 & 80 & 2 & 20 & 0 & 0 & 0 & 0 & 10 \\
\hline 2. & $\begin{array}{l}\text { Penguasaan bahan } \\
\text { ajar }\end{array}$ & 0 & 0 & 8 & 80 & 2 & 20 & 0 & 0 & 0 & 0 & 10 \\
\hline 3. & $\begin{array}{l}\text { Kemampuan } \\
\text { menerapkan } \\
\text { Kurikulum }\end{array}$ & 0 & 0 & 7 & 70 & 3 & 30 & 0 & 0 & 0 & 0 & 10 \\
\hline 4. & $\begin{array}{l}\text { Kemampuan } \\
\text { menerapkan metode }\end{array}$ & 0 & 0 & 6 & 60 & 4 & 40 & 0 & 0 & 0 & 0 & 10 \\
\hline 5. & $\begin{array}{l}\text { Kemampuan dalam } \\
\text { penyelesaian } \\
\text { permasalahan }\end{array}$ & 0 & 0 & 3 & 30 & 5 & 50 & 2 & 20 & 0 & 0 & 10 \\
\hline$n=5$ & Jumlah & 0 & 0 & 32 & $\begin{array}{l}32 \\
0\end{array}$ & 16 & $\begin{array}{l}16 \\
0\end{array}$ & 2 & 20 & 0 & 0 & 50 \\
\hline
\end{tabular}

Keterangan:

$\begin{array}{ll}\text { Sangat mampu } & =0 / 5=0 \% \\ \text { Mampu } & =320 / 5=64 \%\end{array}$

$\begin{array}{ll}\text { Cukup mampu } & =160 / 5=32 \% \\ \text { Kurang mampu } & =20 / 5=4 \% \\ \text { Tidak mampu } & =0 / 5=0 \%\end{array}$

$=160 / 5=32 \%$

Tidak mampu $\quad=0 / 5=0 \%$ 
Dari tabel di atas, terlihat bahwa kompetensi professional pendidik berada pada kategori sangat mampu 0\%, kategori mampu menunjukkan angka 64\%, kategori cukup mampu menunjukkan angka 32\%, kategori kurang mampu menunjukkan angka $4 \%$ dan kategori tidak mampu menunjukkan angka $0 \%$ dari total responden.

\section{KESIMPULAN}

\section{Kesimpulan}

Berdasarkan uraian terdahulu, kemudian dihubungkan dengan data-data yang telah disajikan di atas, maka penulis dapat menarik beberapa kesimpulan sebagai berikut. Pertama, dari sepuluh responden kompetensi pedagogik (keterangan tabel I), kategori sangat mampu $=0 \%$, mampu $=50 \%$, cukup mampu $=$ $24 \%$, kurang mampu $=18 \%$ dan kategori tidak mampu = 8\%; kompetensi kepribadian (keterangan tabel II), kategori sangat baik $=0 \%$, baik $=58 \%$, cukup baik $=$ $32 \%$, kurang baik $=10 \%$ dan tidak baik $=0 \%$; kompetensi sosial (keterangan tabel III), kategori sangat mampu $=6,67 \%$, mampu $=56,66 \%$, cukup mampu $=30 \%$, kurang mampu $=6,67 \%$ dan kategori tidak mampu $=0 \%$; dan kompetensi profesional (keterangan tabel IV), kategori sangat mampu $=0 \%$, mampu $=64 \%$, cukup mampu $=32 \%$, kurang mampu $=4 \%$ dan kategori tidak mampu $=0 \%$. Dengan demikian bahwa kompetensi pendidik yang kategori sangat mampu yang dimiliki oleh pendidik dari 4 kompetensi yaitu dari keterangan tabel I + II + III + IV = $0 \%+0 \%+6,67 \%+0 \%=6,67 \%$ dibagi 4 kompetensi $=1,6675 \%$; kategori mampu yang dimiliki oleh pendidik dari keterangan tabel I + II + III + IV = 50\% + 58\% + $56,66 \%+64 \%=288,66 \%$ dibagi 4 kompetensi $=$ $57,165 \%$; kategori cukup mampu yang dimiliki oleh pendidik dari keterangan tabel I + II + III + IV = 24\% + $32 \%+30 \%+32 \%=118 \%$ dibagi 4 kompetensi $=$
$29,5 \%$; kategori kurang mampu yang dimiliki oleh pendidik dari keterangan tabel I + II + III + IV = 18\% + $10 \%+6,67 \%+4 \%=38,67 \%$ dibagi 4 kompetensi $=$ $9,6675 \%$; kategori tidak mampu mampu yang dimiliki oleh pendidik dari keterangan tabel I + II + III + IV = 8\% $+0 \%+0 \%+0 \%=8 \%$ dibagi 4 kompetensi $=2 \%$.

Kedua, berdasarkan data di atas dari sepuluh responden pendidik PAUD dari empat kompetensi yang dimiliki adalah kompetensi profesional yang menempati persentasi yang tertinggi yaitu dengan menunjukkan angka $64 \%$, sedangkan yang terendah adalah kompetensi pedagogik yaitu dengan menunjukkan angka 50\% dan kompetensi lainnya yaitu kompetensi kepribadian menunjukan angka $58 \%$ dan kompetensi sosial menunjukan angka 56,66\%. Ketiga, berdasarkan data di atas bahwa dari empat kompetensi pendidik PAUD yang dimaksud, masih perlu ditingkatkan.

\section{Saran}

Berdasarkan kesimpulan di atas disarankan, pertam, perlunya pembinaan yang mantap dan terencana dari instansi terkait untuk meningkatkan kompetensi bagi pendidik PAUD. Kedua, para pendidik seharusnya dididik dan dilatih secara merata dan profesional agar terbangun kompetensi yang handal dan terpercaya di masyarakat. Ketiga, materi diklat dan pembinaan pendidik PAUD perlu dikaji secara mendalam agar kompetensinya dapat diakomodir melalui diklat dan pembinaan di lapangan.

\section{DAFTAR PUSTAKA}

BPKB Sulawesi Tenggara. (2008). Data Pendidik PAUD (PTK-PNF). Kendari: BPKB Sulawesi Tenggara

Departemen Pendidikan Nasional. (2005). Standar nasional pendidikan. Jakarta: BSNP.

Departemen Pendidikan Nasional. (2006). Pengembangan kompetensi sosial pendidik pendidikan kesetaraan. Jakarta: Depdiknas.
Sunardjo, Sriwiyanti, \& Latifah. (2002). Pengelolaan peserta didik (Pengelolaan pendidikan). Bandung: IKIP Bandung.

Supena, A. (2005). Materi sosialisasi uji kompetensi guru. Jakarta: DKI Jakarta Selatan.

(2003) Undang-Undang Republik Indonesia Nomor 20 Tahun 2003 Tentang Sistem Pendidikan Nasional. Jakarta: Depdiknas. 